\title{
HUBUNGAN KINERJA PENYULUH PERTANIAN DENGAN KOMPETENSI PETANI KAKAO DI KABUPATEN LUWU UTARA
}

\author{
Sapar $^{1}$, Salju $^{2}$, Silviah $^{3}$ \\ 1) Sekolah Tinggi Ilmu Ekonomi Muhammadiyah Palopo \\ 2,3) Prodi Akuntansi Sekolah Tinggi Ilmu Ekonomi Muhammadiyah Palopo
}

\begin{abstract}
Abstrak: Tujuan penelitian ini adalah menjelaskan hubungan kinerja penyuluh pertanian dengan kompetensi petani kakao di Kabupaten Luwu Utara.Metode yang digunakan dalam penelitian ini adalah metode survey, dengan menjadikan angket sebagai bahan utama pengumpulan data. Populasi dalam penelitian ini adalah seluruh penyuluh pertanian di Kabupaten Luwu utara yaitu berjumlah 112. Dengan menggunakan rumus monogram Hery King, ukuran sampel penyuluh pertanian dengan tingkat kesalahan sepuluh persen sebanyak 22 orang sampel. Data yang diperoleh dianalisa dengan Regresi Linear Sederhana menggunakan SPSS 16.0.Hasil penelitian menunjukkan bahwa peubah kinerja penyuluh pertanian berpengaruh nyata terhadap kompetensi petani kakao. Kinerja penyuluh pertanian ikut menentukan baik buruknya kompetensi petani kakao dengan koefisien pengaruh sebesar 0,645 satuan pada a 0,05.oleh karena itu peubah kinerja penyuluh pertanian harus dijadikan titik fokus dalam meningkatkan kompetensi petani kakao.Dalam hubungan ini kemampuan penyuluh merencanakan program, mengevaluasi dan membuat laporan perlu dikembangkan.Berdasarkan hasil penelitian dan pembahasan, disimpulkan bahwa peubah kinerja penyuluh pertanian berpengaruh nyata dan signifikan terhadapa kompetensi petani kakao di Kabupaten Luwu Utara, oleh karena itu disarankan kepada: a) Badan Ketahanan Pangan dan Pelaksana Penyuluhan Kabupaten Luwu Utara untuk terus meningkatkan kinerja penyuluh pertanian kakao dengan berfokus pada peningkatan kompetensi petani dengan melakukan berbagai macam pelatihan tentang teknis kakao. b) Terhadap penyuluh-penyuluh pertanian agar dapat meningkatkan pengetahuan mereka tentang teknis kakao dan dapat di salurkan kepada seluruh petani kakao binaan penyuluh.
\end{abstract}

Kata Kunci: Kinerja Penyuluh Pertanian, Kompetensi Petani Kakao

\section{PENDAHULUAN}

Kinerja penyuluh pertanian yang baik merupakan dambaan setiap stakeholder pertanian.Petani yang terbelenggu kemiskinan merupakan ciri bahwa penyuluhan pertanian masih perlu untuk terus meningkatkan perannya dalam rangka membantu petani memecahkan masalah mereka sendiri terutama dalam aspek usahatani. Penyuluhan pertanian adalah pendidikan nonformal bagi petani dan keluarganya yang bertujuan untuk meningkatkan kesejahteraan petani dengan titik fokus pada perubahan pengetahuan, sikap dan keterampilan dalam berusahatani.

Kondisi penyuluhan pertanian yang terus mengalami perubahan baik sejak pemerintahan orde lama, orde baru sampai orde reformasi turut mempengaruhi citra penyuluhan pertanian.
Pada masa orde baru penyuluhan pertanian dicitrakan sebagai alat pemerintah dalam membantu pemerintah menciptakan swasembada pangan dengan pendekatan peningkatan produksi usahatani.Penyuluhan pertanian sangat diperhatikan dan dinilai sukses mengantarkan swasembada pangan.Pada masa orde reformasi, penyuluhan pertanian mengalami masa yang suram terutama dengan perubahan kelembagaan penyuluhan dengan keluarnya undang-undang otonomi daerah yang secara langsung berdampak pada kinerja penyuluhpertanian. Kinerja penyuluh psikologis dan organisasi penyuluh yang diklasifikasikan dalam kemampuan dan keterampilan. 


\section{BAHAN DAN METODE}

Jenis penelitian ini adalah "ex post facto," yaitu bentuk penelitian untuk menilai peristiwa yang telah terjadi untuk menemukan faktor-faktor penyebab melalui pengamatan atau penilaian kondisi faktual di lapangan.Pengamatan utama penelitian adalah menjelaskan hubungan kompetensi penyuluh pada kinerja mereka, dan menjelaskan hubungan antara kinerja penyuluh pada kompetensi petani kakao. Metode yang digunakan dalam penelitian ini adalah metode survey.Sumber data diambil melalui wawancara dan pengisian kuisioner.

Populasi penelitian adalah seluruh penyuluh pertanian dan kelompok tani binaan penyuluh yang berada di Kabupaten Luwu Utara Sulawesi Selatan.Pemilihan lokasi tersebut didasarkan pada pertimbangan sebagai representasi sentra produksi kakao di Sulawesi Selatan. Sampel diambil secara random sampling dari seluruh penyuluh yang ada di Kabupaten Luwu Utara sebanyak 112 orang. Data yang dikumpulkan dalam penelitian ini meliputi data primer dan data sekunder, baik kualitatif dan kuantitatif.

\section{HASIL DAN PEMBAHASAN}

Karateristik responden berdasarkan Usia responden

\begin{tabular}{|l|c|c|}
\hline \multicolumn{1}{|c|}{ Usia } & Jumlah & Persentase (\%) \\
\hline $20-30$ & & \\
Tahun & 1 & 4,55 \\
$31-40$ & 10 & 45,45 \\
Tahun & 9 & 40,91 \\
$41-50$ & 2 & 9,09 \\
Tahum & & \\
>50 tahun & & $\mathbf{1 0 0 \%}$ \\
\hline \multicolumn{1}{|c|}{ Total } & $\mathbf{2 2}$ & \\
\hline
\end{tabular}

Berdasarkan tabel diatas dapat dijelaskan beberapa tingkatan Usia dari responden yang menjadi bahan penelitian ini dengan tingkatan persentasenya. Responden yang berusia 20-30 tahun berjumlah 1 orang dengan persentase $4 \%$ dari jumlah keseluruhan responden, yang berusia 31-40 tahun berjumlah 10 orang dengan persentase $45 \%$, yang berusia 41-50 tahun berjumlah 9 orang dengan persentase $40 \%$ dan yang berusia diatas 50 tahun 2 orang dengan persentase $9 \%$ dari keseluruhan responden.

\section{Karateristik responden berdasarkan Masa Kerja}

\begin{tabular}{|l|c|c|}
\hline Masa Kerja & Jumlah & Persentase (\%) \\
\hline <1 Tahun & 0 & 0 \\
1-5 Tahun & 3 & 13,64 \\
6-10 Tahun & 11 & 50 \\
>10 Tahun & 8 & 36,36 \\
\hline Total & $\mathbf{2 2}$ & $\mathbf{1 0 0 \%}$ \\
\hline
\end{tabular}

Berdasarkan tabel diatas dapat dijelaskan bahwa para responden pada penelitian ini tidak ada yang memiliki masa kerja dibawah 1 tahun,untuk masa kerja 1-5 tahun berjumlah 3 orang dengan tingkat persentase 13\%, masa kerja 6-10 tahun berjumlah 11 orang dengan tingkat persentase $50 \%$ dan yang memiliki masa kerja diatas10 tahun berjumlah 8 orang dengan tingkat persentase $36 \%$ dari jumlah keseluruhan responden yang diteliti.

Jadi dari kedua tabel diatas dapat dilihatjumlah keseluruhan dari responden yang karateristiknya berdasarkan pada usia dan masa kerja berjumlah 22 orang dengan tingkat persentase $100 \%$.

\section{Analisis Korelasi}

Berikut ini adalah uraian hasil pengujian korelasi antara kinerja penyuluh pertanian dengan 
kompetensi petani kakao dan output table pengujian dengan menggunakan bantuan program SPSS versi 16.

hubungan antara Kinerja Penyuluh Pertanian dengan Kompetensi Petani Kakao

\begin{tabular}{|c|c|c|c|}
\hline & & $\begin{array}{c}\text { KINER } \\
\text { JA }\end{array}$ & $\begin{array}{c}\text { KOMPETE } \\
\text { NSI }\end{array}$ \\
\hline $\begin{array}{l}\text { KINERJA } \\
\text { PENYULU } \\
\mathrm{H}\end{array}$ & $\begin{array}{l}\text { Pearson } \\
\text { correlati } \\
\text { on } \\
\text { Sig. (2- } \\
\text { tailed) } \\
\mathrm{N}\end{array}$ & 22 & $\begin{array}{r}.645^{*} \\
.000 \\
22\end{array}$ \\
\hline $\begin{array}{l}\text { KOMPETE } \\
\text { NSI } \\
\text { PETANI }\end{array}$ & $\begin{array}{l}\text { Pearson } \\
\text { correlati } \\
\text { on } \\
\text { Sig. (2- } \\
\text { tailed) } \\
\mathrm{N}\end{array}$ & $\begin{array}{r}.645^{*} \\
.000\end{array}$ & 22 \\
\hline
\end{tabular}

Berdasarkan tabel diatas, dapat dijelaskan bahwa nilai korelasi pearson antara kinerja penyuluh pertanian dengan kompetensi petani kakao sebesar 0,645. Tanda bintang berjumlah satu artinya korelasi signifikan pada level 0,05 dengan uji 2 sisi. Nilai korelasi positif artinya terjadi hubungan positif yaitu apabila kinerja penyuluh pertanian meningkat maka kompetensi petani kakao juga akan semakin tinggi. Sedangkan keeratan hubungannya sangat tinggi karena nilainya diatas 0,5 .

\section{Analisis Regresi Sederhana}

Berikut ini adalah hasil pengujian regresi sederhana antara kinerja penyuluh pertanian dengan kompetensi petani kakao dan output tabel coefficient pengujian dengan menggunakan bantuan program SPSS versi 16.
Coefficients antara Kinerja Penyuluh Pertanian dengan kompetensi petani Kakao

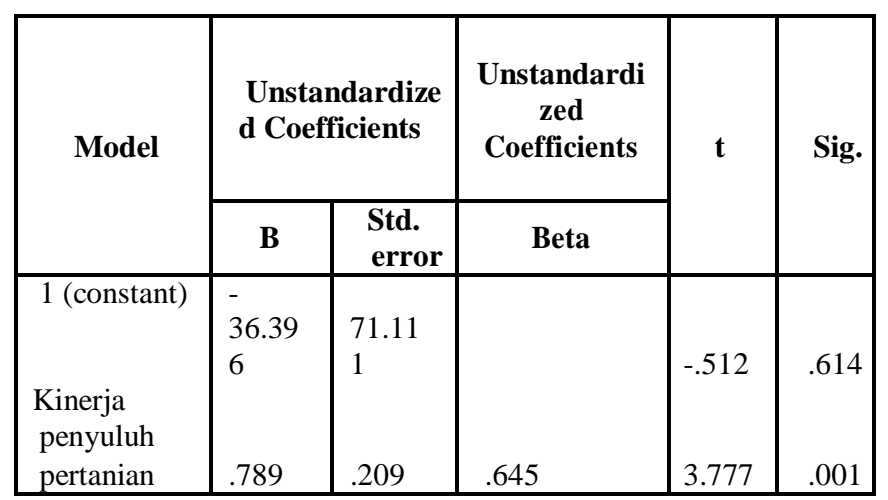

Annova antara Kinerja penyuluh Pertanian dengan Kompetensi Petani Kakao

\begin{tabular}{|c|c|c|c|c|c|}
\hline Model & $\begin{array}{c}\text { Sum of } \\
\text { squares }\end{array}$ & df & $\begin{array}{c}\text { Maen } \\
\text { square }\end{array}$ & F & Sig. \\
\hline $\begin{array}{c}1 . \\
\text { Regression } \\
\text { Residual }\end{array}$ & 24952.321 & 1 & 24952.321 & 14.263 & $.001_{\mathrm{a}}$ \\
Total & 59948.633 & 20 & 1749.432 & & \\
\hline
\end{tabular}

coeficcient Determinasi antara Kinerja penyuluh Pertanian dengan Kompetensi Petani kakao

\begin{tabular}{|c|c|c|c|c|}
\hline Model & R & R Square & $\begin{array}{c}\text { Adjusted R } \\
\text { Square }\end{array}$ & $\begin{array}{c}\text { Std. Error of } \\
\text { the Estimate }\end{array}$ \\
\hline 1 & $.645_{\mathrm{a}}$ & .416 & .387 & 41.826 \\
\hline
\end{tabular}

Berdasarkan tabel diatas, dapat diketahui nilai koefisien regresi, koefisien determinasi, nilai $\mathrm{F}$ hitung, $\mathrm{t}$ hitung, signifikasi dan sebagainya antara kinerja penyuluh pertanian dengan kompetensi petani kakao. Penjelasan hasi analisis regresi dan pengujian $\mathrm{t}$ dan $\mathrm{F}$ sebagai berikut: 


\section{Analisis Regresi Linear Sederhana}

Persamaan regresi sederhana:

$$
\begin{aligned}
& Y=a+b X \\
& Y=-36,396+0,645 X
\end{aligned}
$$

Keterangan:

$\mathrm{Y}=$ Kompetensi Petani Kakao

$\mathrm{X}=$ Kinerja Penyuluh Pertanian

$\mathrm{a}=$ Nilai Konstanta

b = Koefisien Regresi

Penjelasan persamaan tersebut sebagai berikut:

a) Konstanta sebesar -36,396; artinya jika kinerja penyuluh pertanian nilainya 0 , maka kompetensi petani kakao nilainya negative sebesar $-36,396$.

b) Koefisien regresi kompetensi penyuluh pertanian sebesar 0,645; artinya jika kinerja penyuluh pertanian mengalami kenaikan satu satuan, maka kompetensi petani kakao akan mengalami peningkatan sebesar 0,645 satuan. Koefisien bernilai posotif artinya hubungan antara kinerja penyuluh pertanian dengan kompetensi petani kakao adalah positif, artinya semakin tinggi kinerja penyuluh pertanian maka semakin meningkatkatkan kompetensi petani kakao.

\section{Pengujian Hipotesis}

Uji t ( Uji koefisien regresi sederhana)

Uji t digunakan untuk mengetahui pengaruh secara signifikan antara kinerja penyuluh pertanian dengan kompetensi petani kakao.

Langkah-langkah pengujian hipotesis sebagai berikut:

a) Menentukan hipotesis:

Ho: Kinerja penyuluh pertanian tidak berpengaruh terhadap kompetensi petani kakao.
Ha: Kinerja penyuluh pertanian berpengaruh terhadap kompetensi petani kakao.

b) Menentukan tingkat signifikansi; tingkat signifikasi menggunakan 0,05

c) Menentukan t hitung: berdsarkan tabel diatas diperoleh t hitung sebesar 3.777

d) Menentuka $\mathrm{t}$ tabel: tabel distribusi $\mathrm{t}$ dicari pada $\alpha=5 \%: 2=2,5 \%$ (uji 2 sisi) dengan derajat kebebasan (df) n-k-1 atau 22-2-1=19 ( $\mathrm{n}$ adalah jumlah data dan $\mathrm{k}$ adalah jumlah variable bebas. Dengan pengujian 2 sisi ( signifikansi $=0,025)$ hasil diperoleh untuk $\mathrm{t}$ tabel sebesar 2,093

e) Kriteria pengujian;

Ho diterima jika $\mathrm{t}$ tabel $>\mathrm{t}$ hitung

Ho ditolak jika $t$ tabel $<\mathrm{t}$ hitung

f) membandingkan t hitung dengan t tabel: nilai $\mathrm{t}$ hitung $>\mathrm{t}$ table $(3,777>2,093)$

g) Kesimpulan:

Karena nilai $\mathrm{t}$ hitung $>\mathrm{t}$ tabel $(3,777>2,093)$ maka Ho ditolak artinya bahwa kinerja penyuluh pertanian berpengaruh terhadap kompetensi petani kakao.Nilai $\mathrm{t}$ hitung positif, artinya semakin tinggi kinerja penyuluh pertanian maka semakin meningkatkan kompetensi petani kakao.

Langkah-langkah pengujian

hipotesis sebagai berikut:

a) Menentukan hipotesis:

Ho: Kinerja penyuluh pertanian tidak berpengaruh terhadap kompetensi petani kakao.

Ha: Kinerja penyuluh pertanian berpengaruh terhadap kompetensi petani kakao.

b) Menentukan tingkat signifikansi; tingkat signifikasi menggunakan 0,05 
c) Menentukan signifikansi berdasarkan tabel diatas diperoleh nilai signifikansi sebesar 0,01

d) Kriteria pengujian:

Ho diterima jika signifikansi $>0,05$

Ho ditolak jika signifikansi $<0,05$

e) Membandingkan signifikansi. Nilai signifikansi 0,01 kurang dari 0,05, maka Ho ditolak

f) Kesimpulan:

Karena nilai signifikansi 0,01<0,05 maka Ho ditolak, artinya bahwa kinerja penyuluh pertanian berpengaruh terhadap kompetensi petani kakao.

\section{Pembahasan}

Hasil penelitian menunjukan bahwa peubah kinerja penyuluh pertanian berpengaruh nyata terhadap kompetensi petani kakao. Kinerja penyuluh pertanian ikut menentukan baik buruknya kompetensi petani kakao dengan koefisien pengaruh sebesar 0,645 satuan pada $\alpha$ 0,05

Pengaruh kinerja penyuluh pertanian terhadap kompetensi petani kakao tersebut tampak pada baik buruknya kemampuan usahatani kakao, kemampuan berpartisipasi dalam penyuluhan dan kelompok tani, kemampuan merencanakan usaha, kemampuan mengorganisir dan memasarkan hasil, kemampuan keuangan, kemampuan berkomunikasi dan memotivasi, kemampuan membentuk kelembagaan ekonomi, dan kemampuan mengakses pupuk herbisida dan insektisida. Jika terjadi peningkatan satu satuan kinerja penyuluh pertanian akan meningkatakan kompetensi petani kakao sebesar 0,645 satuan pada $\alpha 0,05$.
Kemempuan usahatani kakao meliputi kemampuan mempersiapkan lahan kakao, kemempuan membibitkan lahan kakao, kemempuan menenm kakao, kemampuan mengkonversi dan menyiapkan lahan, kemampuan memangkas kakao, kemampuan memupuk, kemempuan mengendalikan hama,penyakit dan gulma.

Kemampuan berpartisipasi dalam penyuluhan dan kelompok tani meliputi kemampuan aktif membayar iuaran anggota, kemampuan untuk aktif disetiap pertemuan, kemampuan menyumbangkan pemikiran dalam kelompok tani, kemampuan mengikuti kegiatan penyuluhan pertanian.

Kemampuan merencanakan usaha meliputi kemampuan menghubungkan kebutuhan dan kenyataan untuk menentukan target atau tujuan usahatani kakao, kemampuan merumuskan rangkaian tindakan dalam usahatani kakao, dan kemampuan menguasai kalkulasi keuangan dan analisis usaha.

Kemampuan mengorganisir dan memasarkan hasil meliputi kemampuan membagi pekerjaaan dan tanggungjawab, kemampuan menguasai informasi dan membuat profil pasar, kemampuan membaca fluktuasi dan harga kakao, kemampuan memutuskan waktu yang tepat menjual kakao, dan kemampuan menjual produk pada pasar berbeda dengan harga menguntungkan.

Kemampuan keuangan meliputi kemampuan menabung, kemampuan mengakses kredit usahatani kakao, kemampuan membuat pembukuan usahatani kakao, dan kemampuan membaca prospek keuangan usahatani kakao. 
Kemampuan membentuk kelembagaan ekonomi meliputi, kemampuan membentuk kelompok tani, kemempuan membentuk koperasi simpan pinjam.

Kemampuan mengakses pupuk, herbisida dan insektisida meliputi kemampuan mengakses pupuk, herbisida dan insektisida dan kemampuan membuat pupuk, herbisida dan insektisida alami.

Dimensi peubah kinerja penyuluh pertanian yang berpengaruh pada proses dan hasi dari pelaksanaan penyuluhan pertanian, terdiri dari:

Persiapan penyuluh pertanian yang meliputi membuat rencana pembelajaran usaha tani kakao; tersusunnya rumusan hasil pengumpulan data potensi wilaya dan agroekosistem; membuat rumusan hasil kebutuhan teknologi spesifik lokasi yang sesuai dengan kebutuhan petani; membuat programa penyuluhan yang mengakomodir kebutuhan petani; menyusun rencana kerja yang jelas, terukur dan terealisasi; dan menyusun metode penyuluhan yang sesuai dengan materi penyuluhan dan karateristik petani

Pelaksanaan penyuluhan pertanian meliputi melaksanakan pembelajaran usaha tani kakako; menyuluhkan materi penyuluhan yang sesuai dengan kebutuhan dan karakteristik petani; mnerapkan metode penyuluhan yang bervariasi dan sesuai dengan materi penyuluhan dan karakteristik petani dan mengembangkan kelompok tani menjadi kelompok yang lebih besar terkait dengan pengembangan usaha taninya.

Evaluasi dan pelaporan penyuluhan pertanian meliputi melakukan evaluasi efektifitas program; mengumpulkan data tentang input, aktivitas, kehadiran peserta dan reaksi terhadap program; membuat laporan dan rencana tindak lanjut; mengavaluasi dampak penyuluhan dan mengkomunikasikan hasil evaluasi kepada pihakpihak terkait.

Pengembangan penyuluhan pertanian meliputi menyusun pedoman teknis dan pelaksana penyuluhan untuk acuan penyuluh dalam melaksanakan tugasnya; merumuskan hasil kajian arah kebijakan penyuluhan; dan merumuskan hasil konsep baru metode penyuluhan.

Pengembangan profesi penyuluhan pertanian meliputi ikut serta atau aktif dalam perkumpulan profesi tingkat kabupaten, provinsi dan nasional; mengunjungi sumber-sumber informasi teknologi pertanian; mengakses informasi menggunakan internet; mengikuti kegiatan magang atau studi banding; dan membuat tulisan alamiah atau popular dan diterbitkan dalam majalah atau surat kabar.

Kemampuan penyuhan pertanian meliputi penerapan gayakepemimpinan; menerapkan keteranmpilanmemimpin; menumbuh kembangkan kelompok tani; dan mengembangkan kepemimpinan kelompok tani.

Diseminasi teknologi meliputi penggunaan media cetak atau audio visual; melakukan pameran teknologi pertaian; tingkat penggunaan komunikasi tatap muka; melakukan studi banding; dan tingkat pengunaan petak percontohan.

Komunikasi penyuluh pertanian meliputi membuat media penyuluhan; memahami dan mendengarkan petani; menjelaskan, member inspirasi, berterima kasih dan toleran terhadap petani; mendorong dan membantu petani untuk maju dan mencapai tujuan; dan mendisiplinkan diri dan memotivasi petani. 
Kemitraan usaha meliputi mencari mitra usaha; mengidentifiasi dan mengginventarisir sumber-sumber permodalan lokal; membimbing pemupukan mdal usaha; dan membimbing penyesiaan agro input, penyimpanan dan pemasaran hasil.

Melakukan teknis budidaya kakao meliputi mempersiapkan lahan; membibitkan kakao; melakukan penanaman; melakukan konservasi dan persiapan lahan; melakukan pemangkasan dan pemupukan; melakukan pengendalian hama, peyakit, dan gulma; melakukan panen dan pasca panen seperti pemetikan dan sortasi buah kakao, pemeraman atau penyimpanan,pemecahan buah, fermentasi, perendaman dan pencucian buah kakao, pengeringan, tempering dan sortasi buah kakao.

Hasil penelitian in sejalan dengan hasil penelitian Teddy Rachman Muliady (2009) yang menyimpulkan bahawa kompetensi penyuluh pertanian berpengaruh positif pada kerja mereka. Penelitian Bestinaet al.,(2006) jiga mendukung penelitian ini.

Peubah kinerja penyuluh yang berpengaruh nyata pada kompetensi petani kakao, memperkuat teori Robbins (Veithzal, 2004), Siagian (2002), Gibson (2001) dan Atmosoeprapto (2004).Keempat teori tersebut pada umumnya menyatakan bahwa kinerja adalah fungsi interaksi antara kemampuan atau ability, motivasi atau motivation dan kesempatan atau opportunity, tugas yang tepat dan lingkungan kerja. Kemampuan yang tinggi dan didukung oleh motivasi yang tinggi pula akan memberikan sesuatu yang baik berupa produktivitas yang lebih baik (produktif).
Menurut hasi penelitian pengaruh kinerja penyuluh pertanian menyumbangkan pengaruh yang besar pada kompetensi petani kakao.Hal ini ditunjukkan oleh koefisien pengaruh sebesar 0,645 satuan, oleh karena itu peubah kinerja penyuluh pertanian harus dijadikan titik fokus dalam meningkatkan kompetensi petani kakao.Dalam hubungan ini kemampuan penyuluh merencanakan program, mengevaluasi dan membuat laporan perlu dikembangkan.

\section{SIMPULAN}

Berdasarkan hasil penelitian dan pembahasan, disimpulkan bahwa peubah kinerja penyuluh pertanian berpengaruh nyata dan signifikan terhadapa kompetensi petani kakao di Kabupaten Luwu Utara.

\section{SARAN}

Berdasarkan kesimpulan diatas maka disarankan kepada: a) Badan Ketahanan Pangan dan Pelaksana Penyuluhan Kabupaten Luwu Utara untuk terus meningkatkan kinerja penyuluh pertanian kakao dengan berfokus pada peningkatan kompetensi petani dengan melakukan berbagai macam pelatihan tentang teknis kakao. b) Terhadap penyuluh-penyuluh pertanian agar dapat meningkatkan pengetahuan mereka tentang teknis kakao dan dapat di salurkan kepada seluruh petani kakao binaan penyuluh. 


\section{DAFTAR PUSTAKA}

Buku

Armstrong M, Baron. 1998. A Hand Book of Personal Management Practice, Fouth Edition. London: Kogan Page. 2004.

Performance Management [terjemahan: Tony Setiawan]. Yogyakarta: Tugu.

Gibson JL. 2001. Cooperative Extension Program Planning in Wisconsin. USA. University of Wisconsin.

John MI, James HD. 2002.Organisasi:Perilaku, Struktur dan Proses. Jilid I, Edisi Kedelapan. Jakarta: Binarupa Aksara.

Hasibuan SPM. 2001. Organisasi dan Motivasi,Dasar Peningkatan Produktivitas. Jakarta: Bumi Aksara.

Kartasapoetra AG. 1988. Teknologi Penyuluhan Pertanian. Jakarta: Bina Aksara.

Mangkunegara A, Prabu A. 2000. Manajemen Sumberdaya Manusia Perusahaan. Bandung: Rosda

Padmowihardjo S. 1994. Psikologi Belajar Mengajar. Jakarta: Universitas Terbuka. 2004. Menata Kembali Penyuluhan Pertanian di Era Pembangunan Agribisnis. Jakarta: Departemen Pertanian.

Prawirosentono S. 2007. Manajemen Operasi Analisis dan Studi Kasus. Jakarta: Bumi Aksara.

Rogers EM. Shoemaker FF. 1995. Communications of Innovations.New Edition. New York: The Free Press

Siagian SP. 2002. Kiat Meningkatkan Produktivitas Kerja. Jakarta: Rineka Cipta.

. 2004. Teori Motivasi dan Aplikasinya. Jakarta: Rineka Cipta.

Spencer LM, Spencer SM. 1993. Competence At Work, Models For Superior Performance. New York: John Willey \& Sons, Inc.
Sugiyono. 2009. Metode Penelitian Kuantitatif, Kualitatif dan R\&D. Bandung. Alfabeta.

Sulistiyani R. 2003. Manajemen Sumberdaya Manusia. Konsep, Teori dan Pengembangan dalam Konteks Organisasi Publik. Yogyakarta: Graha Ilmu.

Veithzal R. 2004. Performance Appraisal. Jakarta: Rajagrafindo Persada.

van den Ban AW, Hawkins HS. 1999. Penyuluhan Pertanian. Terjemahan, Herdiasti AD. Yogyakarta: Kanisius.

Wibowo. 2007. Manajemen Kinerja. Jakarta: Raja Grafindo Persada.

\section{Jurnal, Artikel, Laporan Hasil Penelitian dan Prosiding}

Deborah JM, Keith N, Jim L, Ken B. 2002. Core Competencies for The Cooperative 201-1-do.html. Diakses 6 Juni 2009

Lasmahadi, A. 2002. Sistem Manajemen Sumberdaya Manusia Berbasis Kompetensi. http://www.sdm.go.id. Diakses 2 Pebruari 2011

[NCCE] North Carolina Cooperative Extention. 2006. Extention Agent Competencies. http://www.ces.ncsu.edu/pods/agents/kno wledge.com.html.Diakses 30 mei 2009

Muliady Rachmat Teddy. 2009. Penelitian tentang kompetensi penyuluh berpengaruh positif pada kinerja penyuluh.

Sapar. 2011. "Faktor-Faktor yang Berpengaruh pada Kinerja Penyuluh Pertanian dan Dampaknya pada Kompetensi Petani Kakao di Empat Wilayah Sulawesi

Selatan.”J. Forum Pascasarjana, Vol 34 No. 4 hal: 297-305

\section{Peraturan-Peraturan}

(BPSDM) Badan Pengembangan Sumberdaya Manusia Pertanian. 2007. Pedoman Penyelenggaraan Pendidikan dan 
Vol. 05 No. 01

Pelatihan Dasar Bagi Penyuluh Pertanian. Jakarta: BPSDM Deptan.

(Deptan) Departemen Pertanian. 1988. Pedoman Pengelolaan Balai Penyuluhan Pertanian. Jakarta: Departemen Pertanian.

2003. Pedoman Umum Penyuluhan Pertanian dalam Bentuk Peraturan Perundangan tentang Jabatan Fungsional Penyuluhan Pertanian dan Angka Kreditnya. Jakarta: Badan Pengembangan Sumberdaya Manusia Pertanian. Jakarta: Departemen Pertanian. 